\title{
Play at Your Own Risk: Sport and the Injury Epidemic
}

\author{
Ronald F. Zernicke, Kathryn A. Antle, Scott G. McLean, Riann \\ M. Palmieri-Smith, James A. Ashton Miller, \\ and Edward M. Wojtys \\ University of Michigan
}

\begin{abstract}
Each year, more than 30 million children and adolescents participate in organized sports in the United States (US), and more than 4.3 million nonfatal sports- and recreation-related injuries are treated in US hospital emergency departments. Two types of activity-related injuries, in particular, that we study in the Bone and Joint Injury Prevention and Rehabilitation Center at the University of Michigan are anterior cruciate ligament (ACL) injuries and head injury and concussion. Knee ACL injuries are occurring in epidemic-like proportions. In the US alone there are approximately 200,000 new ACL injuries at a total cost of over \$1 billion per year. ACL-injured patients are at a significant risk of developing early onset osteoarthritis. Exacerbating the concern is the increase in ACL injury rates in youth and adolescents; particularly girls can experience ACL injury rates from two to five times greater than boys in the same sport. In addition, 3.8 million sports- and recreation-related concussions occur in the US each year. Significantly more research is needed, but intriguing findings are surfacing. For example, high school athletes' recovery times for a concussion are longer than college athletes' recovery times. Moreover, high school athletes who sustain a concussion are 3 times more likely to sustain a second concussion. Preliminary studies state suggest women have a higher risk for head injury and post concussion syndrome due to potentially weaker neck muscles, different muscle activation patterns, and hormone variations. Three key questions must be answered to understand these and other sports-related injuries: 1) What is the magnitude of the epidemic? 2) What are the causes of injury? and 3) What can we do to prevent injuries? Without a greater awareness of the injury risk and a better understanding of the injury mechanisms, the risk of sport-related injuries may escalate in the coming years.
\end{abstract}

Participation in sport can be beneficial for adults and children to promote exercise and healthy lifestyles. The benefits of exercise include decreasing the incidence of cardiovascular disease, obesity, osteoporosis, and diabetes and fostering a healthy image for children and youth. Although exercise and physical activity can have major benefits, some disadvantages do exist, including the

The authors are with the University of Michigan Bone \& Joint Injury Prevention \& Rehabilitation Center, 24 Frank Lloyd Wright Drive, Lobby A, Ann Arbor, MI, 48105. 
occurrence of injury. Here, we provide an overview on what has been called the "injury epidemic in sport" and the need for more research to gain clearer insights into the mechanisms of injury and the effectiveness of injury prevention programs.

Annually, more than 150 million adults participate in non-work-related physical activity and recreation (CDC, 2000). Injuries are inevitable. Musculoskeletal conditions in the United States (US) cost our society more than $\$ 250$ billion per year (Whiting \& Zernicke, 2008), and musculoskeletal disabilities will increase dramatically over the next 20 years as our population ages. Forty-six million people have arthritis (many involving posttraumatic arthritis) and that number will increase to more than 60 million by 2020 (Hogan \& Gross, 2003). A better understanding of how and why injuries occur, and why they lead to long-term sequelae like osteoarthritis, should lead to both improved injury prevention and mobility later in life.

When trying to understand sport-related injuries, three questions must be answered: 1) What is the magnitude of the epidemic? 2) What are the causes of injury? and 3) What can we do to prevent injuries? Here, these questions will be addressed for two types of injuries being investigated at the University of Michigan: anterior cruciate ligament (ACL) injuries to the knee joint, and head injury and concussion. In an injury prevention program, each question must ultimately be answered to have an effective, comprehensive, and systematic reduction in the number of injuries.

\section{Sports Injury Epidemic}

What is the magnitude of the epidemic? Due to the multitude of participantsboth adults and children-in recreational and sport activities, there are many injuries that may have a number of causes, including lack of training, improper technique, or overuse. More than 4 million nonfatal sports- and recreation-related injuries are treated each year in US hospital emergency departments (Gotsch, Annest, Holmgreen, \& Gilchrist, 2002). Each year in the US, more than 30 million children and adolescents participate in organized sports, resulting in more than 750,000 sport-related injuries in individuals under 15 years of age (NIH, 1992). Thirty to fifty percent of sport-related injuries in children and youth are due to overuse (Patel \& Baker, 2006). These injuries cost society up to $\$ 1.8$ billion per year. Many injuries are due to modifiable equipment and environmental factors$16 \%$ of sports injury emergency room visits and $20 \%$ of hospitalizations may be preventable (Janda, Bir, \& Kedroske, 2001). In the NCAA, thousands of athletes participate in sports every year. The NCAA budget has increased approximately $15 \%$ annually since 1982 (Zimbalist, 2001). With this increase in financial worth and with increasing national profile, schools are attracting athletes who are stronger, faster, and better trained. If an athlete weighs more and is traveling at a faster speed than before, the kinetic energy during impact increases drastically placing greater demands on the musculoskeletal system.

Some sports injuries are more evident in children, especially during their growth spurt (e.g., physeal injuries), but many injuries occur throughout the life span. Recurring sports injuries include stress injuries, overuse injuries, contusions, sprains, and strains. Stress injuries occur from repetitive microtrauma to a 
localized area. Overuse occurs when there is repetitive submaximal microtrauma with a lack of sufficient rest between activity bouts. These injuries can result from inadequate training, environmental factors, or individual anatomical factors. Fortunately, some factors that produce overuse or stress injuries are modifiable through equipment, training, or technique. Many of these injuries are treated by rest, physical therapy, and rehabilitation (Patel \& Baker, 2006).

\section{Injury Mechanisms}

What are the causes of injury? Sports injuries occur in a variety of circumstances, but are influenced by both intrinsic and extrinsic risk factors. Age, biologic maturity, body size, gender, fitness level, and mechanical properties of tendons and ligaments are examples of intrinsic risk factors. Extrinsic risk factors include the environment, such as the playing surface and weather, equipment, or rules of play. Some of these factors are modifiable and, thus, are the focus of prevention strategies (e.g., coaches working on an athlete's technique or strength or changing a shoe type for a specific surface; Caine, Caine, \& Maffulli, 2008; Meeuwisse, 1994).

\section{Injury Prevention}

What can we do to prevent injuries? Clinicians, trainers, and researchers have found that injury prevention programs should emphasize, for example, proper coaching, training, hydration, officiating, equipment, medical coverage at sporting events, and preseason physical examinations. Educational, behavioral, environmental, and enforcement or legislative interventions have been developed. One example of an injury prevention intervention is a neuromuscular training program in Finland (Pasanen, Parkkari, Rossi, \& Kannus, 2008). This program was developed to decrease the number of lower extremity injuries specifically in females. The risk of injury decreased $66 \%$ in athletes who followed the training program. The greatest effect was a decrease in ankle ligament injuries. The training program lasted approximately 20-30 minutes before sport-specific exercises were begun. Athletes participated in an intensive training program at the beginning of the season and reduced the training program to one of maintenance during the competitive season (Pasanen et al., 2008). Several other interventions are being introduced into sports either to create a safer playing environment to decrease injury rates through the use of helmets, the prohibition of head-to-head contact, and the use of prophylactic bracing and orthotics. One major problem in designing injury prevention programs is the difficulty in getting widespread adoption of the intervention even after the intervention has been proven on a small scale. One example of this phenomenon includes the breakaway base in softball and baseball. Breakaway bases when compared with standard bases demonstrated a decrease in injuries by $96 \%$ and a decrease in medical care costs by $99 \%$ (Janda, Hankin, \& Wojtys, 1988). Nonetheless, it is difficult to gain nationwide attention, because it is difficult to persuade people that the intervention actually works and is worth their time. Interventions also need to be funded, which poses another problem. 


\section{ACL Injury Epidemic}

What is the magnitude of the epidemic? Knee injuries, especially ACL ruptures, have increased in number and visibility in the past few decades. Up to 250,000 ACL injuries occur in the US every year. Besides the extensive rehabilitation needed after surgical reconstruction, longitudinal evidence suggests that osteoarthritis (OA) develops 5-15 years after ACL injury regardless of whether the patient received an ACL reconstruction (Frank \& Jackson, 1997; Griffin et al., 2000). Athletes may be at an increased risk for further injury because they return to play with approximately $20 \%$ less strength in their injured leg.

The following is just one "real life" example of a young athlete with an ACL injury and repair. A talented young woman was an active member of several sports teams at her high school. By the time she was 15 years old, she had suffered ACL tears on both knees, and she had reconstructive surgery on each knee to enable her to keep playing sports. According to current data, she has a strong likelihood of experiencing her first problems with OA by the time she is in her twenties. Unfortunately, this is a not uncommon occurrence for females her age.

Title IX (DOL, 1972) has resulted in a significant increase in female participation in sports, which has been beneficial for their physical well-being. However, due to the increase in female participation and exposure rate, the injury rate has also increased (Hewett, 2008). Examining the causes of these injuries is an important focus of research. Are females more likely to be injured because they are not properly trained? Do their anatomical and biomechanical differences mean that females need to be trained differently than males because they move differently?

\section{ACL Injury Mechanisms}

What causes ACL injuries? What are the risk factors and are these factors modifiable? Many studies have reported that ACL injury risk is linked to environmental, anatomical, hormonal, neuromuscular, or biomechanical risk factors. Environmental risk factors include shoe-surface interactions, weather, and bracing. Anatomical risk factors include the quadriceps femoris angle (Q-angle), joint orientation, growth rate, body mass index (BMI), ACL notch size, ACL biomaterial properties, and posterior tibial slope. Neuromuscular risk factors (e.g., altered movement patterns, altered muscle activation patterns, and altered proprioception or somatosensory deficits) are closely linked with biomechanical risk factors that include dynamic loading and dynamic activities (Griffin et al., 2006). To date, the actual mechanism for a classic ACL rupture is unknown. Is the ligament healthy and just overloaded, or does the ligament fail under normal loading because it has already been weakened by microtrauma caused by repetitive loading? Either or both scenarios could be the case, and better imaging modalities may give us better insights.

Surface interactions are influenced significantly by weather changes. The weather can alter the friction between the shoe and turf (Orchard, 2002; Orchard, Seward, McGivern, \& Hood, 1999). Typically, unless the venue of the sports event is changed (e.g., indoor vs. outdoor), weather is something that athletes or coaches cannot modify. They can, however, change the shoes that athletes wear or the playing surface. Investigations are being conducted on the effects of artificial 
versus natural turf on injury rates (Griffin et al., 2006; Meyers \& Barnhill, 2004; Olsen, Myklebust, Engebretsen, \& Bahr, 2003). Artificial turfs and floors have been shown to increase the risk for ACL injuries on higher traction surfaces. An increased risk for injury in women on artificial floors compared with wooden floors has been reported; artificial floors produced 2.35 times higher risk for women injuring their ACL. The artificial floors, in general, had greater frictional coefficients (Olsen et al., 2003) with the result that considerably higher shear forces can be transmitted from the floor, via the shoe, to the lower extremity. Controversy exists with the rates of injury on artificial turfs. Assessing a new generation turf revealed no difference in the severity, incidence, nature, or cause of injuries due to training on the new artificial turf versus grass in either men or women (Fuller, Dick, Corlette, \& Schmalz, 2007).

Because shoe-surface interaction is modifiable, more research should also be done in this area. Increasing the shoe-surface coefficient of friction may improve performance, but may also increase the risk of ACL injury. This risk can be direct, which could involve an athlete changing movement patterns due to the interaction between the shoe and surface, or indirect, which could involve an athlete changing his or her movement due to the amount of traction (Griffin et al., 2006; Lambson, Barnhill, \& Higgins, 1996).

Bracing (orthotics) is an area being studied to assess whether injuries are reduced with orthoses, such as prophylactic or functional knee braces. Prophylactic knee braces are used for rehabilitation purposes to limit the range of motion, but they have been shown to not prevent varus-valgus motion. Functional braces are used as a preventative measure during some activities. Conflicting evidence exists about braces and their effectiveness in ACL injury prevention. Functional braces can reduce anterior-posterior (AP) translation laxity in ACL deficient knees in weight bearing or nonweight bearing activities, but not in the transition between weight bearing and nonweight bearing activities. Interestingly, prophylactic braces have been shown to decrease injuries in cadets playing intramural football, but other studies have shown that a functional brace had no effect on the incidence of graft tear (McDevitt et al., 2004). Substantial evidence does not yet exist to support the use of knee braces to prevent ACL injuries (Albright et al., 1994; Beynnon, Fleming, Churchill, \& Brown, 2003; Beynnon, Fleming, Labovitch, \& Parsons, 2002; Griffin et al., 2006; McDevitt et al., 2004; Najibi \& Albright, 2005; Sitler et al., 1990; Wright \& Fetzer, 2007; B. Yu et al., 2004).

Anatomical risk factors for ACL injuries include the quadriceps femoris angle (Q angle), kinematic orientation, increased growth rates, increased BMI, ACL notch size, ACL properties, and posterior tibial slope. The Q angle can influence limb kinematics and may have an effect on other ACL risk factors, such as knee valgus position. Females frequently have greater $\mathrm{Q}$ angles, creating a greater valgus orientation that puts the athlete at a higher risk for ACL injury, as noted in biomechanical studies and clinical and video analyses (Berns, Hull, \& Patterson, 1992; Besier, Llyod, Cochrane, \& Ackland, 2001; Beynnon, Howe, Pope, Johnson, \& Fleming, 1992; Beynnon et al., 1997; Durselen, Claes, \& Hartmuth, 1995; Ford, Myer, \& Hewett, 2003; Hewett et al., 2005; Malinzak, Colby, Kirkendall, Yu, \& Garrett, 2001; Markolf et al., 1995; McLean, Huang, Su, \& Van den Bogert, 2004; McLean et al., 2005). Increased pronation increases internal tibial rotation and potentially results in greater anterior knee joint laxity. Patients incurring ACL 
injuries are more likely to have greater pronation. Rapid growth during puberty increases the height of the center of mass, making it more difficult to control the trunk, and increases the joint forces due to the increased mass. However, this results in problems due to the lack of strength in the person, decreasing stability especially in the core region (trunk and hip stabilizers). Some suggest that this decreased core stability may be the cause of the increased hip adduction and knee abduction increasing the valgus load (Griffin et al., 2006; Myer, Chu, Brent, \& Hewett, 2008). A greater BMI has been shown to increase injury risk, and women, in general, tend to have a higher BMI. Increased BMI may lead to a greater amount of knee extension at landing, which has been shown to increase risk for injury (Knapik et al., 2001; Ostenberg \& Roos, 2000; Uhorchak et al., 2003). Differing opinions exist on whether notch size and ACL size are related to ACL injury (Anderson, Dome, Gautam, Awh, \& Rennirt, 2001; Anderson, Lipscomb, Liudahl, \& Addlestone, 1987; Chandrashekar, Slauterbeck, \& Hashemi, 2005; CharIton, St. John, Ciccotti, Harrison, \& Schweitzer, 2002; Harner, Paulos, Greenwald, Rosenberg, \& Cooley, 1994; LaPrade \& Burnett, 1994; Lund-Hanssen et al., 1994; Muneta, Takauda, \& Yamamoto, 1997; Schickendantz \& Weiker, 1993; Shelbourne, Davis, \& Klootwyk, 1998; Souryal \& Freeman, 1993; Teitz, Lind, \& Sacks, 1997; Uhorchak et al., 2003). Some report that ACL injured persons have a smaller notch width than healthy controls, but others refute that. A recent study found that the smaller the notch, the smaller the ACL midsubstance cross sectional area. In comparison with men, women have a smaller ACL and potentially a lower absolute mechanical strength. Women have thinner ACL midsubstance than men of the same height and normalized body weight (Dienst et al., 2007; Griffin et al., 2006). Posterior tibial slope is a recent area of interest in ACL injury prevention. Very different slopes can exist between the lateral and medial tibial plateaus. High correlations have been shown between slope and anterior tibial translation (Renstrom et al., 2008).

Many researchers suggest that hormones may have an influence on ACL injuries, which may explain some of the discrepancy in ACL injury incidence rates between men and women. Women have smaller ACLs with less linear stiffness, less elongation, lower energy absorption, and load at failure. Women, typically, have greater joint laxity and decreased muscular stiffness. Knee laxity and hormone research studies are currently limited to studies with small sample sizes, limited testing days due to menstrual cycle, lack of hormone confirmation to define cycle phase, lack of comparison between sexes, and inconsistent definition of menstrual cycle phase. Estrogen alone is probably not responsible for changes in ACL structure, metabolism, and mechanical properties, but it remains unknown how other hormones affect these changes. Some data suggest that females have more knee laxity than males and greater laxity during periods of the menstrual cycle. How this increase in knee laxity affects joint stability and injury risk remains to be determined (Griffin et al., 2006; W. D. Yu, Liu, Hatch, Panossian, \& Finerman, 1999; W. D. Yu, Panossian, Hatch, Liu, \& Finerman, 2001). Potentially, ACL laxity, neuromuscular factors, and athletic performance may fluctuate during menstrual cycle. A large number of ACL injuries are found during perimenstrual (Myklebust, Maehlum, Holm, \& Bahr, 1998; Slauterbeck et al., 2002) and preovulatory (Beynnon et al., 2006; Wojtys, Huston, Boynton, Spindler, \& Lindenfeld, 2002) days of the cycle. The distribution of observed ACL injuries has been 
reported by day of cycle in one study (see Figure 1). Estrogen, progesterone, folliclestimulating hormone, and luteinizing hormone profiles during a complete cycle are illustrated along with frequency of injury (Adachi, Nawata, Maeta, \& Kurozawa, 2008; Wojtys et al., 2002; Zazulak, Hewett, Reeves, Goldberg, \& Cholewicki, 2007).

Neuromuscular risk factors, such as movement patterns and muscle activation patterns, are being quantified to better understand ACL injury mechanisms. Gender differences are also apparent within neuromuscular risk factors. Studies have shown differences in knee and hip flexion, knee valgus, internal rotation of the hip and external rotation of the tibia, knee joint stiffness, quadriceps and hamstrings activity and activation patterns, decreased muscle strength, greater atrophy, and diminished balance capacity in ACL injuries between men and women (Griffin et al., 2006). Some of the alterations in motor patterns may be protective mechanisms. A difference in activation patterns between quadriceps and hamstrings has been demonstrated. Adjustments in neuromuscular factors due to injury may contribute to the more obvious impairments, such as strength loss, atrophy, and altered function (Chmielewski, Stackhouse, Axe, \& Snyder-Mackler, 2004; Drechsler, Cramp, \& Scott, 2006; Maitland, Ajemian, \& Suter, 1999; McHugh, Tyler, Nicholas, Browne, \& Gleim, 2001; Swanik, Lepart, Giraldo, DeMont, \& Fu, 1999; Snyder-Mackler, De Luca, Williams, Eastlack, \& Bartolozzi,

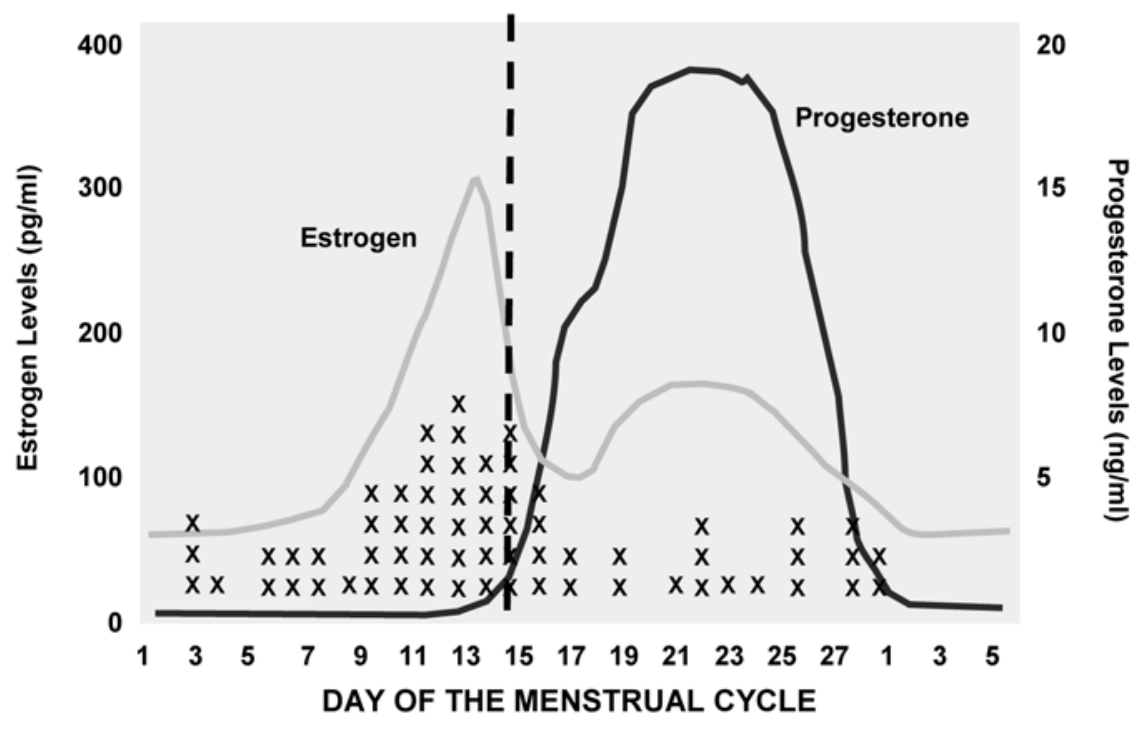

Figure 1 - Histogram of observed ACL injuries plotted by day of cycle as determined by urine metabolite levels. Representative hormone fluctuations of estrogen (gray) and progesterone (black) seen during a complete cycle are overlaid with the histogram to give a representation of the individual hormone levels at the time of injury ( $\mathrm{X}$ indicates an injury). Individual cycle lengths were normalized for a 28-day cycle for these graphical purposes (Wojtys et al., 2002). 
1994; Urbach, Nebelung, Becker, \& Awiszus, 2001; Urbach, Nebelung, Weiler, \& Awiszus, 1999).

Some muscle loss is attributed to arthrogenic muscle inhibition (AMI), which is a result of ACL injury. AMI is a reflex inhibition of musculature surrounding a joint following swelling or damage to that joint (Palmieri et al., 2004; Palmieri et al., 2005). Studies have shown that women had increased quadriceps activation and decreased hamstring activation resulting in patterns where the quadriceps dominate, and knee stiffness decreases. Conversely, males had a higher stiffness, and, therefore, were better able to resist angular perturbations at the foot. These somatosensory and neuromuscular deficits and biomechanical abnormalities may help explain why ACL injured patients are likely to experience early onset OA in the knee joint (Griffin et al., 2006; Ingersoll, Grindstaff, Pietrosimone, \& Hart, 2008).

Biomechanical risk factors are modifiable and may be extremely influential to ACL injury risk. Anatomical sites other than the knee may also contribute to injury because the human body is a "kinetic chain;" all of the links are connected and influence one another. If one link of the chain is disrupted, it may affect the kinematics of the other links to compensate. Biomechanical risk factors include dynamic loading factors and dynamic activities. Dynamic factors include joint alignment and orientation, joint kinematics, and joint kinetics. Females have decreased knee and hip flexion angles, increased valgus angle, increased quadriceps activation, and decreased hamstrings activation when compared with males. Many of these risk factors may be modifiable with coaching proper technique (Griffin et al., 2006).

Dynamic loading factors involve the loads transmitted across joints that change over time and with joint orientation. The loading factors are influenced by the central nervous system, nerve-muscle interaction, muscles, and joints. Again, these factors may be modifiable with proper training. Athletes can learn proper positioning and movement behavior to avoid positions and movements with increased risk for injury. Neuromuscular factors include reaction time, motor unit recruitment, and balance. Athletes can train and modify their muscular endurance, absolute strength, amount of tension and muscle activation patterns; focusing more on performance rather than a specific type of muscle contraction. Training should address the dynamic muscle contraction focusing on increasing knee stiffness (maximal cocontraction of muscles), improving balance, minimizing at-risk positions, and decreasing ACL strain (Griffin et al., 2006).

Dynamic activities have been studied, such as cutting and landing from a jump, that demonstrate enhanced hamstring strength, knee stiffness, and endurance of the muscles crossing the knee result in the smallest amount of anterior tibial translation. ACL strain is greater in full extension of the knee and with quadriceps or isometric hamstring contraction. When describing an ACL injury, the information should include vital aspects of the playing situation, athlete and opponent behavior, gross biomechanical characteristics, and detailed biomechanical characteristics (joint/tissue biomechanics). All of this information will help with diagnosis and may provide a better understanding of ACL injuries (Griffin et al., 2006). 


\section{ACL Injury Prevention}

What can be done to prevent ACL injuries? The exact mechanisms for ACL injuries are elusive, but we do know that ACL injuries are complex and influenced by multiple factors. Much current research is based on "safe" (noninjurious) movement patterns in a laboratory environment, but this gives limited information on injury mechanisms. Implementing real-play movement patterns is extremely important to better understand the mechanisms. Researchers then want to teach the patient proper technique and how to avoid these high-risk positions. Strategies are being developed for activating protective neuromuscular responses in high risk situations, such as maximizing quadriceps strength and hamstrings strength. Many research groups are trying not only to understand the injury mechanisms, but also educate athletes, working with real time feedback, teaching proper body techniques, basic injury mechanisms, and strategies to avoid injury (Griffin et al., 2006; McLean, 2008). With various testing techniques, such as model-based image matching techniques, markerless motion capture, and wearable motion sensors, researchers may be able to capture limb joint mechanics during sports activity, which may reveal actual injury scenarios. There are also models being developed to assess motion as a supplement to laboratory testing (McLean, 2008).

Most ACL prevention strategies are based on altering dynamic loading through neuromuscular training. These programs usually include stretching and strengthening activities, aerobic conditioning, agility training, plyometrics, and risk awareness training. Currently, there is insufficient evidence supporting the premise that ACL prevention programs improve performance or alter what are thought to be key risk factors for injury. Early data show that specific training programs that enhance body control reduce ACL injury rates in female athletes and may increase athletic performance. Some studies are looking into ways to strengthen the quadriceps muscle and minimize arthrogenic muscular inhibition (Palmieri-Smith, Thomas, \& Wojtys, 2008).

Recent evidence suggests that neuromuscular training including plyometrics, balance, technique training, and awareness of injury can decrease risk of injury in females. However, it is unknown what the specific exercises, sequence of exercises, intensity, or duration should be. The underlying mechanisms of balance, strength, and neuromuscular coordination are supported, but not clearly understood. Training may facilitate neuromuscular adaptations that provide increased joint stabilization, muscular preactivation, and reactive patterns that may protect an athlete's ACL from increased loading. Prevention programs center on alteration of neuromuscular risk factors, but each one is unique; for example, some are sport or age specific, but others are not. Most are designed for female athletes because of their injury susceptibility (Palmieri-Smith et al., 2008; Renstrom et al., 2008). Due to the major differences between individuals, not just between males and females, researchers are debating the importance of developing either individualized or generalized programs. Prevention strategies may need to be different between males and females with regard to injury risk factors (McLean, 2008). Currently, many of the interventions and prevention programs are based on results of male performance. That approach may not be optimal for all. Females may already compensate for having geometric, laxity, and tissue differences. 
Prevention strategies should extend beyond gender and focus more on individual injury predisposition (McLean, 2008).

A recent review studied six existing intervention programs. Four groups incorporated plyometric movements and demonstrated reduced ACL injury risk. The plyometric exercises train the muscles, connective tissue, and nervous system to accomplish the stretch shortening cycle. Researchers emphasized the importance of focusing on proper technique and mechanics. The programs that were most effective at decreasing the ACL injury risk incorporated biomechanical feedback to the patients. Studies have shown that combined education and feedback training appear to be more effective than education only. Some studies have shown that balance exercises alone are not as effective in preventing injuries as when combined with other prevention techniques. Balance training is not only a factor in preventing ACL injuries but has been shown to increase muscle strength and increase full body stability. Strength training is extremely effective in decreasing ACL injury risk, but is more effective when combined with other prevention modalities (Hewett, Myer, \& Ford, 2006).

Neuromuscular training can decrease the differences between males and females in force absorption, active joint stabilization, muscle imbalances, and functional biomechanics, and also can increase the strength of the structural tissues. Programs have shown a decrease in injury risk, but there were limitations to all of the studies - especially the generalizability from the relatively small sample sizes. The most effective component of training remains unknown. Studies need to be conducted on which components are the most important and what combination results in the best injury prevention program. After assessing the studies, the review suggested that females can reduce ACL injury risk if: 1) plyometrics, balance, and strengthening exercises are combined into a program; 2) they participate in the program more than one time a week; and 3) they participate in the program for at least 6 weeks (Hewett et al., 2006).

Many preventative measures and rehabilitation techniques can positively impact performance. This will be important especially when introducing prevention programs to coaches and athletes. Combining performance and prevention techniques is seen in some of the current ACL injury prevention programs. Programs need to be easy for the coaches to implement into their training strategy. If coaches think that it takes too long, is too expensive, or is too difficult for their teams, then they will be less likely to be compliant. Programs need to not only focus on injury prevention, but also athletic performance so that the athletes see an improvement during training (Hewett et al., 2006).

Sokolove (2008) recently gave several recommendations for parents concerning injury prevention in his book Warrior Girls, which focused on the ACL injury epidemic in female athletes. Although Sokolove focused on ACL injuries, his discussion may be generalized to parents of children participating in many youth sports. Parents need to look actively for prevention programs because coaches may not be aware of them or may choose not to implement the programs into their training. Parents can have a substantial influence on coaches and should demand that coaches implement prevention programs into their children's training. Parents should also not direct their children to participate in only one sport, especially if the team trains year round. Single sport activity increases the risk for overuse injuries and exposure to certain injuries. Some believe playing multiple sports can 
keep athletes well-rounded. Sokolove also recommended that parents use the same tactics in dealing with their child during a sports season as they do during daily parenting. Parents need to set limits on what their children do. Having a child go to two or three practices a night may not be the optimal way for the child to train and may increase their risk for injury. Parents can influence or limit coaches in training and competition schedules, especially if they have a group of equally concerned parents (Sokolove, 2008).

Many children are influenced by peers and media sources that suggest and promote certain body types. Parents can help their children by giving them a healthy perspective of exercise, fitness, and body awareness. More media publicity and mainstream exposure of injuries and research are needed. Influential leaders in the sports field, especially in women's sports, need to become involved and help make the risk of injury known to the public. In addition, more research needs to be done regarding injuries and public education needs to be available so that people can help themselves (Sokolove, 2008).

\section{Head Injury and Concussion Epidemic}

What is the magnitude of the epidemic? More than 1.2 million Americans suffer head injuries each year. More than 50,000 of these head injuries result in fatalities and many more result in disabilities. The lifetime prevalence of depression and feelings commonly associated with a depressed state increases as a function of previous head injury exposure (Guskiewicz et al., 2007). Females have a greater likelihood of postconcussion syndrome at 1 month follow-up, depression following mild traumatic brain injury (mTBI), and persisting symptoms 1 year after mTBI (Broshek et al., 2005).

Clinicians and researchers have found it difficult to determine a conclusive set of symptoms, diagnoses, and treatment options due to the large amount of variation in the definitions of concussion or mTBI (Comper, Bisschop, Carnide, \& Tricco, 2005). Although there are a variety of definitions for head injury and concussion, many of the definitions hold common features. Most agree that concussions result in alteration of mental status after injury, memory dysfunction (e.g., retrograde or anterograde amnesia), loss of consciousness (LOC) less than 30 minutes (this is controversial; some argue strongly that LOC is not essential to experience a concussion), observed signs of neurologic dysfunction, and a Glasgow Coma Scale (GCS) score of 13-15 (30 minutes post injury; Packard, 2008).

Multiple concussions may result in significant depression, cognitive impairment, or neuropathological changes. Children who experience a concussion, skull fracture, or intracranial injury are two times more likely to have another head injury within 12 months of the first injury. People with multiple concussions also seem to have more symptoms, including loss of consciousness, confusion, and amnesia (Swaine et al., 2007). Suicide risk predisposition factors are similar to some of the traumatic brain injury predisposition factors, affecting mainly young adult males. These factors include the presence of temporary or permanent cognitive and behavioral impairments, and long-term psychosocial consequences such as unemployment, relationship issues, and social isolation, or emotional distress, substance abuse, and psychiatric morbidity (Simpson \& Tate, 2007). mTBI is also 
a potential risk factor for the occurrence of neurodegenerative disorders such as Alzheimer's or Parkinson's diseases (Guskiewicz et al., 2007).

Approximately 2 million sports and recreational concussive injuries occur each year in the US. Concussive injuries are six times more likely to happen in organized sports in children 6-16 years old, and 180 of 100,000 children are hospitalized each year for head injury (Lovell \& Fazla, 2008). Children have been shown to experience many of the same issues as adults after a head injury. One major issue that has been studied is the increase in behavioral problems after injury, especially in those children who were socially disadvantaged and had some behavior issues before injury. Some children may not have resources easily available to help in dealing with the effects of concussion. Clinicians and researchers believe that children should not be able to return to play until they are completely symptom free. They should also refrain from not only physical exertion, but mental exertion from school. More research is needed to investigate head injury differences between children and adults (Schwartz, Taylor, Drotar, \& Owen, 2003).

\section{Head Injury and Concussion Injury Mechanisms}

What are the causes of injury? Concussions are due to the sudden acceleration or deceleration of the head in translation or rotation. Injuries are seen in three main areas after the concussive event: directly adjacent to the impact site (coup injury), opposite side of the brain (contrecoup injury), or in the midbrain above the brainstem (McCrory et al., 2005). Consensus exists in the common features defining the nature of concussive head injuries. Concussions are usually known to result from a direct blow to the head or a blow where the force is transmitted to the brain. A concussive injury also results in neuropathological changes and an impairment of neurologic function that may not last for a long period of time. Researchers, however, suggest the injury is more functional than structural. A set of symptoms and signs have been designated for diagnosing concussions, but there is still debate about whether loss of consciousness is necessary for a concussion diagnosis. Recovery is usually stepwise. Research and clinical work have demonstrated that concussions are associated with fairly normal neuroimaging studies (McCrory et al., 2005).

Concussion can be a metabolic brain injury, rather than a structural one, with acute, posttraumatic changes occurring in intra- and extracellular environments, leaving the cells vulnerable after injury. The initial loss of neurons can lead to structural changes often seen in major depression. Changes result from ionic shifts associated with increased $\mathrm{Na} / \mathrm{K}$ ATPase activation and resultant hyperglycolysis (Bergschneider et al., 2003; Giza \& Hovda, 2004). A decrease in cerebral blood flow can be seen after the concussive event along with an accumulation of endothelial calcium, which can cause widespread cerebral neurovascular constriction (Giza \& Hovda, 2004; Reddy, Collins, \& Gioia, 2008). The disparity between energy demand and energy supply has been thought to cause a cellular exposure that is particularly susceptible to even minor changes in cerebral blood flow and increases in intracranial pressure and apnea (Cantu \& Voy, 1995; Giza \& Hovda, 2004; Hovda, Yoshino, Kawamata, Katayama, \& Becker, 1991). The brain 
transitions into a state of depressed metabolism that may lead to a long lasting and worsening energy problem after the initial increased use of glucose (Reddy et al., 2008).

Epidemiological studies have shown that women are at a greater risk for concussion, but until recently, this had not been investigated thoroughly. Researchers wanted to determine whether gender differences existed in head neck segment kinematic and neuromuscular control variables in response to an external force with and without neck muscle preactivation (Tierney et al., 2005). A difference was noted in the stabilization of the head-neck segment dynamic stabilization during head acceleration in response to an external force application. Women had a greater head and neck segment peak angular acceleration (50\%) and displacement $(39 \%)$, activated their muscles much earlier, used a greater percentage of maximal head and neck segment muscle activity (79\% peak activity and $117 \%$ muscle activity area), had less isometric strength (49\%), had less neck girth (30\%), had less head mass (43\%), and had lower head neck stiffness (29\%; Tierney et al., 2005).

Hormones may influence head injuries, with a correlation of greater injury risk during certain periods of the menstrual cycle. One group studied whether there was an effect on postural stability and neurocognitive status during any point of the menstrual cycle after a concussive injury, but no significant change was noted during any part of the cycle (Mihalik, Ondrak, Guskiewicz, \& McMurray, in press).

Early identification of the problem is extremely important so that care can be given immediately. A thorough evaluation is necessary so that no symptoms are missed. With early identification and a thorough evaluation, clinicians will be able to manage the concussion and symptoms properly and potentially prevent additional injury. Research has shown the physical exertion or activity may delay recovery. In general, it takes approximately 3 weeks to recover fully. Clinicians need to be cautious when allowing the patient to return to play (Reddy et al., 2008).

One major challenge in diagnosing head injuries is that prior head trauma and depression may be accompanied by similar cognitive complaints. Signs and symptoms of mTBI include cognitive symptoms, somatic symptoms, mood disruption, and sleep dysregulation. Cognitive symptoms include "fogginess" (e.g., slower reaction times, attenuated memory performance, slower processing speed via computerized neurocognitive testing; Packard, 2008; Reddy et al., 2008), confusion (impaired awareness and orientation to surroundings, although memory systems are not directly affected; Lovell \& Fazla, 2008; Reddy et al., 2008), difficulty concentrating, memory deficits including retrograde and anterograde amnesia (Lovell \& Fazla, 2008; Packard, 2008; Reddy et al., 2008), and cognitive fatigue (Reddy et al., 2008). Somatic symptoms include headaches (most common; Guskiewicz, Weaver, Padua, \& Garrett, 2000; Reddy et al., 2008), dizziness, nausea, and sensitivity to light and sound (Reddy et al., 2008). People with mood disruption experience irritability, sadness, and anxiety. Sleep dysregulation includes difficulty falling asleep, fragmented sleep, hypersomnia, or hyposomnia (Reddy et al., 2008). Loss of consciousness is another sign of concussion (Lovell \& Fazla, 2008; Reddy et al., 2008). Diagnosing concussions or head injuries in children can be difficult. The diagnosis is usually based on input from parents or 
coaches. It is difficult to determine the diagnosis for children who have not fully developed conceptually or with limited communication skills (Lovell \& Fazla, 2008; McCrory et al., 2005).

A mild traumatic brain injury is characterized by some damage to the structure and function of the brain. Clinicians and researchers debate about the effectiveness of imaging techniques and what techniques are better for diagnoses. A computed tomography (CT) image is only suggested if the issue is supported by clinical factors such as suspicion of intracranial structural lesions. Researchers have shown insufficient evidence for recommending magnetic resonance imaging (MRI), but there are newer MRI techniques that are being studied with greater sensitivity. New functional imaging techniques including photon emission tomography (PET), single photon emission computed tomography (SPECT), or functional MRI (fMRI) are being developed. Most researchers, scientists, and physicians generally concur, however, that any individual who is difficult to assess should be imaged (Peloso et al., 2004).

There are no consistent recommendations for neuropsychological evaluations. Many of the studies involve variations in methods leading to inconclusive results. All guidelines suggest neuropsychological assessment is important in patients with persistent complaints to outline deficits and provide advice on treatment plans. The assessment should aid clinicians in decision making, but should not be the only indicator for return to activity. Since concussions are a complex injury, the diagnosis and treatment decisions should encompass all signs and symptoms of head injuries. Instead of exclusively doing a baseline assessment, researchers are studying the effectiveness of performance variability during the follow-up period that may be extremely important if no baseline was collected (McCrory et al., 2005). The advantages of neurocognitive assessment are that it allows for large number of patients to be evaluated, it can provide a solid baseline for an individual or a team in a reasonable time, it allows for randomization of testing to help improve the reliability of data across multiple evaluation periods, it promotes accurate measurements of cognitive processes, and it allows for clinical information to be sent quickly to sports medicine clinicians. The disadvantages of neurocognitive assessment are that it can be inappropriate when used as a "stand alone" diagnostic instrument; the system may not incorporate other important data such as the clinical overview, symptom presentation, patient history, or results of other diagnostic studies (Peloso et al., 2004; Reddy et al., 2008).

Genetic testing may be an effective injury risk predictor. Researchers have found that ApoE4 is a risk factor for adverse outcome following all levels of brain injury and the development of chronic traumatic brain disease. A calcium subunit gene abnormality may also be important. Researchers are not sure how important these markers are in concussive sports injuries so more research is needed (McCrory et al., 2005).

Various treatments are currently being used. Studies involving drug treatments have had conflicting results on the effectiveness of the therapy. Amitriptyline has been studied most extensively, but none of the methods is consistent. There are two situations when drugs were prescribed (McCrory et al., 2005): 1) in the management of specific symptoms such as not being able to sleep in a complex concussion, or 2) when modifying underlying pathophysiology of the condition with the aim of shortening the duration of the concussion symptoms. 
Little evidence exists whether cognitive rehabilitation has been successful for treating mTBI. Patient education may help, however. Patients who receive information have fewer symptoms or less severe symptoms than those who do not. Patients and clinicians must be knowledgeable about the current treatments and guidelines so the patient can safely return to physical activity without risking further injury (Comper et al., 2005).

Other interventions regarding more social integration and support are also available. An outward bound course has helped to improve psychosocial symptoms by teaching patients to overcome personal obstacles and increasing self esteem and self efficacy. Some groups are working with community integration, quality of life, satisfaction, and social support. Manual therapy has also been shown to decrease more pain-like symptoms, such as headaches (Comper et al., 2005; Guskiewicz et al., 2007).

Suicide prevention interventions are not only directed at head injury patients, but they are also important for clinicians to be aware of due to the high percentage of depression and suicidal thoughts in concussive patients. Universal interventions look at the population as a whole; this program focuses on screening and beginning a timely and appropriate acute and post acute specialized rehabilitation program. Selected interventions target at-risk groups such as mTBI patients who are depressed. Indicated interventions focus on the highest level of risk patients such as those identified as a suicide risk. A full clinical interview may be warranted including a risk assessment interview evaluating the extent and intensity of suicidality, mental state, risk factors, and protective factors (Simpson \& Tate, 2007).

\section{Head Injury and Concussion Prevention}

What can be done to prevent head injury and concussions? Interventions focus on creating a safer playing environment for athletes. Screening or creating baseline levels for all athletes and teams would provide data on whether someone is predisposed to a concussive injury and provide a level that should be reached before the athlete returns to play. Studies recommend a baseline cognitive assessment and symptom score, and a cognitive evaluation, especially in high risk sports. In some cases, sports organizations have changed rules to create safer environments - for example, enforcing helmet use, no head-to-head contact in football, and no head checking in hockey. Researchers have examined the effect of headgear on head injuries. They found that head gear may not be an effective way to decrease head injury risk for all people. Women had greater head acceleration values than men both with and without head gear but exhibited greater accelerations with the head gear on. More research needs to be done to determine the optimal intervention (McIntosh \& McCrory, 2005).

Ostensibly, strength training may help decrease head injury risk in soccer heading. However, one study examined the effect of strength training on head injury risk in collegiate soccer players and found that the program did not enhance the head neck segment dynamic stabilization during an external force application (Tierney et al., 2005). The researchers recommended trying more traditional and neuromuscular training such as plyometrics that focuses on reducing head acceleration during a force application (Tierney et al., 2005). 
Individual factors that may affect return to play guidelines include age, gender, and the presence of learning disabilities. Children may undergo more prolonged and diffuse cerebral swelling after mTBI that increases the risk for secondary injury. Due to a variation in response physiologically, researchers recommend a conservative return to play guideline. This may mean increasing the amount of rest time with symptoms and when symptom free or the length of the physical and mental exertion before returning to sport. Gender differences may exist in concussion, including the predisposing risk factors as well as the results after injury (McCrory et al., 2005; Reddy et al., 2008). Researchers recommend individualized concussion management due to so many variables that influence concussion (Reddy et al., 2008).

Current return-to-play guidelines state that the patient must be completely symptom free at rest and recommend a graduated return to physical and cognitive exertion before contact participation according to the following protocol: light aerobic activity, sport specific exercise, non contact training drills, full contact after medical clearance, and then finally game play. Prescreening has become an important part of return-to-play guidelines. If a baseline is created, the clinician has something on which to base the patient's current status. Much of this has been accomplished using computer-based technology. Clinicians, parents, and coaches should combine all of the tests to get an accurate decision on returning to play. Medical care and return-to-play decisions should be based on a comparison between pre- and postinjury neurocognitive data and the recovery curve of each individual athlete rather than relying on generic return-to-play criteria (McCrory et al., 2005).

\section{Conclusions}

Although there are many benefits from exercise and many injuries leave no functional impairments, some injuries cause musculoskeletal or neurological problems that last a lifetime. Proper training and knowledge of predisposing risk factors are extremely important for all to understand, especially with more than 30 million children and 150 million adults participating in recreational activities each year, and injuries costing the US over $\$ 250$ billion annually. Researchers are investigating a number of ways to improve injury prevention programs, but funding is limited and programs are not nearly as advanced as they could be. Understanding why an injury occurs is vital to be able to develop the optimal injury prevention program. For current interventions, major-scale, long-term, longitudinal studies need to be conducted to determine their effectiveness. These studies should involve multicenter collaborations to maximize sample size to gain results that are significant and generalizable. Multicenter collaborations will also help to increase awareness about the risk of injury in relation to the benefits of exercise and how to prevent injuries to achieve and maintain optimal health.

At the Bone \& Joint Injury Prevention \& Rehabilitation Center, University of Michigan, head injury and concussion and ACL injuries are two injuries being investigated. Although we have some insights about the mechanisms of injury and possible prevention strategies, much more research needs to be done on these prevalent, complex injuries. While the Center is focusing on these two areas, many more injuries to the musculoskeletal system are experienced during both 
recreational and work-related activities. The same level of research needs to be performed on all injuries to provide the maximal benefit to the greatest number of people.

\section{Acknowledgments}

Funded, in part, by National Institutes of Health (R01 AR 05421-01), NFL Charities and the University of Michigan Bone \& Joint Injury Prevention \& Rehabilitation Center

\section{References}

Adachi, N., Nawata, K., Maeta, M., \& Kurozawa, Y. (2008). Relationship of the menstrual cycle phase to anterior cruciate ligament injuries in teenaged female athletes. Archives of Orthopaedic and Trauma Surgery, 128, 473-478.

Albright, J.P., Powell, J.W., Smith, W., Martindale, A., Crowley, E., Monroe, J., et al. (1994). Medial collateral ligament knee sprains in college football: Effectiveness of preventive braces. American Journal of Sports Medicine, 22(1), 12-18.

Anderson, A.F., Dome, D.C., Gautam, S., Awh, M.H., \& Rennirt, G.W. (2001). Correlation of anthropometric measurements, strength, anterior cruciate ligament size, and intercondylar notch characteristics to sex differences in anterior cruciate ligament tear rates. American Journal of Sports Medicine, 29(1), 58-66.

Anderson, A.F., Lipscomb, A.B., Liudahl, K.J., \& Addlestone, R.B. (1987). Analysis of the intercondylar notch by computed tomography. American Journal of Sports Medicine, 15(6), 547-552.

Bergschneider, M., Hovda, D.A., Shalmon, E., Kelly, D.F., Vespa, P.M., Martin, N.A., et al. (2003). Cerebral hyperglycolysis following severe human traumatic brain injury: A positron emission tomography study. Journal of Neurosurgery, 86, 241-251.

Berns, G.S., Hull, M.L., \& Patterson, H.A. (1992). Strain in the anteriomedial bundle of the anterior cruciate ligament under combination loading. Journal of Orthopaedic Research, 10, 167-176.

Besier, T.F., Lloyd, D.G., Cochrane, J.L., \& Ackland, T.R. (2001). External loading of the knee joint during running and cutting maneuvers. Medicine and Science in Sports and Exercise, 33(7), 1168-1175.

Beynnon, B.D., Fleming, B.C., Churchill, D.L., \& Brown, D. (2003). The effect of anterior cruciate ligament deficiency and functional bracing on translation of the tibia relative to the femur during nonweightbearing and weightbearing. American Journal of Sports Medicine, 31, 99-105.

Beynnon, B.D., Fleming, B.C., Labovitch, R., \& Parsons, B. (2002). Chronic anterior cruciate ligament deficiency is associated with increased anterior translation of the tibia during the transition from non- weightbearing to weightbearing. Journal of Orthopaedic Research, 20, 332-337.

Beynnon, B.D., Howe, J.G., Pope, M.H., Johnson, R.J., \& Fleming, B.C. (1992). The measurement of anterior cruciate ligament strain in vivo. International Orthopaedics, 16, $1-12$.

Beynnon, B.D., Johnson, R., Braun, S., Sargent, M., Berstein, I.M., Skelly, J.M., et al. (2006). The relationship between menstrual cycle phase and anterior cruciate ligament injury: A case-control study of recreational alpine skiers. American Journal of Sports Medicine, 34, 757-764.

Beynnon, B.D., Johnson, R., Fleming, B.C., Stankewich, C.J., Renstrom, P., \& Nichols, C.E. (1997). The strain behavior of the anterior cruciate ligament during squatting and active flexion-extension: A comparison of an open and closed kinetic chain exercise. American Journal of Sports Medicine, 25, 823-829. 
Broshek, D.K., Kaushik, T., Freeman, J.R., Erlanger, D., Webbe, F., \& Barth, J.T. (2005). Sex differences in outcome following sports-related concussion. Journal of Neurosurgery, 102, 856-863.

Caine, D., Caine, C., \& Maffulli, N. (2008). Epidemiology of injury in child and adolescent sports: Injury rates, risk factors, and prevention. Clinics in Sports Medicine, 27, 19-50.

Cantu, R.C., \& Voy, R. (1995). Second impact syndrome: A risk in any contact sport. Physician and Medicine, 23, 27-34.

CDC. (2000). Behavioral Risk Factor Surveillance System. from http://www.cdc.gov/brfss

Chandrashekar, N., Slauterbeck, J., \& Hashemi, J. (2005). Sex-based differences in the anthropometric characteristics of the anterior cruciate ligament and its relation to intercondylar notch geometry: A cadaveric study. American Journal of Sports Medicine, 33, 1492-1498.

Charlton, W.P.H., St. John, T.A., Ciccotti, M.G., Harrison, N., \& Schweitzer, M. (2002). Differences in femoral notch anatomy between men and women: Magnetic resonance imaging study. American Journal of Sports Medicine, 30, 329-333.

Chmielewski, T.L., Stackhouse, S., Axe, M.J., \& Snyder-Mackler, L. (2004). A prospective analysis of incidence and severity of quadriceps inhibition in a consecutive sample of 100 patients with complete acute anterior cruciate ligament rupture. Journal of Orthopaedic Research, 22, 925-930.

Comper, P., Bisschop, S.M., Carnide, N., \& Tricco, A. (2005). A systematic review of treatments for mild traumatic brain injury. Brain Injury : [BI], 19(11), 863-880.

Dienst, M., Schneider, G., Altmeyer, K., Voelkering, K., Georg, T., Kramann, B., et al. (2007). Correlation of intercondylar notch cross sections to the ACL size: A high resolution MR tomographic in vivo analysis. Archives of Orthopaedic and Trauma Surgery, 127, 253-260.

DOL. (1972). Title IX, education amendments of 1972. Retrieved January 12, 2009, from http://www.dol.gov/oasam/regs/statutes/titleIX.htm

Drechsler, W.I., Cramp, M.C., \& Scott, O.M. (2006). Changes in muscle strength and EMG media frequency after anterior cruciate ligament reconstruction. European Journal of Applied Physiology, 98, 613-623.

Durselen, L., Claes, L., \& Hartmuth, K. (1995). The influence of muscle forces and external loads on cruciate ligament strain. American Journal of Sports Medicine, 23, 129136.

Ford, K.R., Myer, G.D., \& Hewett, T.E. (2003). Valgus knee motion during landing in high school female and male basketball players. Medicine and Science in Sports and Exercise, 35(10), 1745-1750.

Frank, C.B., \& Jackson, D.W. (1997). Current concepts review-the science of reconstruction of the anterior cruciate ligament. Journal of Bone and Joint Surgery. American Volume, 79(10), 1556-1576.

Fuller, C.W., Dick, R.W., Corlette, J., \& Schmalz, R. (2007). Comparison of the incidence, nature and cause of injuries sustained on grass and new generation artificial turf by male and female football players. Part 2: Training injuries. British Journal of Sports Medicine, 41, i27-i 32 .

Giza, C.C., \& Hovda, D.A. (2004). The pathophysiology of traumatic brain injury. In M.R. Lovell, R.J. Echemendia, J.T. Barth, \& M.W. Collins (Eds.), Traumatic brain injury in sports (pp. 45-70). Lisse: Swets \& Zeitlinger.

Gotsch, K., Annest, J.L., Holmgreen,P., \& Gilchrist, J. (2002). Nonfatal sports- and recreationrelated injuries treated in emergency departments-United States, July 2000-June 2001. Morbidity and Mortality Weekly Report, 51(33), 736-740.

Griffin, L.Y., Agel, J., Albohm, M.J., Arendt, E.A., Dick, R.W., Garrett, W.E., et al. (2000). Noncontact anterior cruciate ligament injuries: Risk factors and prevention strategies. The Journal of the American Academy of Orthopaedic Surgeons, 8(3), 141-150. 
Griffin, L.Y., Albohm, M.J., Arendt, E., Bahr, R., Beynnon, B., DeMaio, M., et al. (2006). Understanding and preventing noncontact anterior cruciate ligament injuries: A review of the Hunt Valley II Meeting, January 2005. American Journal of Sports Medicine, 34, 1512-1532.

Guskiewicz, K.M., Marshall, S.W., Bailes, J., McCrea, M., Harding, H.P., Matthews, A., et al. (2007). Recurrent concussion and risk of depression in retired professional football players. Medicine and Science in Sports and Exercise, 39(6), 903-909.

Guskiewicz, K.M., Weaver, N.L., Padua, D.A., \& Garrett, W. (2000). Epidemiology of concussion in collegiate and high school football players. American Journal of Sports Medicine, 28(5), 643-650.

Harner, C.D., Paulos, L.E., Greenwald, A.E., Rosenberg, T.D., \& Cooley, V.C. (1994). Detailed analysis of patients with bilateral anterior cruciate ligament injuries. American Journal of Sports Medicine, 22, 37-43.

Hewett, T.E. (2008). Predisposition to acl injuries in female athletes versus male athletes. Orthopedics, 31, 26-28.

Hewett, T.E., Myer, G.D., \& Ford, K.R. (2006). Anterior cruciate ligament injuries in female athletes: Part 1, mechanisms and risk factors. American Journal of Sports Medicine, 34(2), 299-311.

Hewett, T.E., Myer, G.D., Ford, K.R., Heidt, R.S., Colosimo, A.J., McLean, S.G., et al. (2005). Biomechanical measures of neuromuscular control and valgus loading of the knee predict anterior cruciate ligament injury risk in female athletes: A prospective study. American Journal of Sports Medicine, 33, 492-501.

Hogan, K.A., \& Gross, R.H. (2003). Overuse injuries in pediatric athletes. The Orthopedic Clinics of North America, 34(3), 405-415.

Hovda, D.A., Yoshino, A., Kawamata, T., Katayama, Y., \& Becker, D.P. (1991). Diffuse prolonged depression of cerebral oxidative metabolism following concussive brain injury in the rat: A cytochrome oxidase histochemistry study. Brain Research, 567, $1-10$.

Ingersoll, C.D., Grindstaff, T.L., Pietrosimone, B.G., \& Hart, J.M. (2008). Neuromuscular consequences of anterior cruciate ligament injury. Clinics in Sports Medicine, 27, 383-404.

Janda, D.H., Bir, C., \& Kedroske, B. (2001). A comparison of standard vs. breakaway bases: An analysis of a preventative intervention for softball and baseball foot and ankle injuries. Foot \& Ankle International, 22, 810-816.

Janda,D.H.,Hankin,F.M., \&Wojtys,E.M.(1988).A prospectivestudy:Basesliding injuriesstationary versus break-away bases. Journal of the American Medical Association, 259, 1848-1850.

Knapik, J.J., Sharp, M.A., Canham-Chervak, M., Hauret, K., Patton, J.F., \& Jones, B.H. (2001). Risk factors for training-related injuries among men and women in basic combat training. Medicine and Science in Sports and Exercise, 33, 946-954.

Lambson, R.B., Barnhill, B.S., \& Higgins, R.W. (1996). Football cleat design and its effect on anterior cruciate ligament injuries: A three year prospective study. American Journal of Sports Medicine, 24, 155-159.

LaPrade, R.F., \& Burnett, Q.M. (1994). Femoral intercondylar notch stenosis and correlation to anterior cruciate ligament injuries: A prospective study. American Journal of Sports Medicine, 22, 198-203.

Lovell, M.R., \& Fazla, V. (2008). Concussion management in the child and adolescent athlete. Current Sports Medicine Reports, 7(1), 12-15.

Lund-Hanssen, H., Gannon, J., Engebretson, L., Holen, K.J., Anda, S., \& Vatten, L. (1994). Intercondylar notch width and the risk factor for anterior cruciate ligament rupture: A case-control study in 46 female handball players. Acta Orthopaedica Scandinavica, 65(5), 529-533. 
Maitland, M.E., Ajemian, S.V., \& Suter, E. (1999). Quadriceps femoris and hamstring muscle function in a person with an unstable knee. Physical Therapy, 79(1), 66-75.

Malinzak, R.A., Colby, S.M., Kirkendall, D.T., Yu, B., \& Garrett, W. (2001). A comparison of knee joint motion patterns between men and women in selected athletic tasks. Clinical Biomechanics (Bristol, Avon), 16, 438-445.

Markolf, K.L., Burchfield, D.M., Shapiro, M.M., Shepard, M.F., Finerman, G.A.M., \& Slauterbeck, J. (1995). Combined knee loading states that generate high anterior cruciate ligament forces. Journal of Orthopaedic Research, 13(6), 930-936.

McCrory, P., Johnston, K., Meeuwisse, W., Aubry, M., Cantu, R., Dvorak, J., et al. (2005). Summary and agreement statement of the 2nd international conference on concussion in sport, Prague 2004. British Journal of Sports Medicine, 39, 196-204.

McDevitt, E.R., Taylor, D.C., Miller, M.D., Gerber, J.P., Ziemke, G., Hinkin, D., et al. (2004). Functional bracing after anterior cruciate ligament reconstruction: A prospective, randomized, multicenter study. American Journal of Sports Medicine, 32, 1887-1892.

McHugh, M.P., Tyler, T.F., Nicholas, S.J., Browne, M.G., \& Gleim, G.W. (2001). Electromyographic analysis of quadriceps fatigue after anterior cruciate ligament reconstruction. The Journal of Orthopaedic and Sports Physical Therapy, 31(1), 25-32.

McIntosh, A.S., \& McCrory, P. (2005). Preventing Head and Neck Injury. British Journal of Sports Medicine, 39, 314-318.

McLean, S.G. (2008). The ACL injury enigma: We can't prevent what we don't understand. Journal of Athletic Training, 43(5), 538-540.

McLean, S.G., Huang, X., Su, A., \& Van den Bogert, A. (2004). Sagittal plane biomechanics cannot injure the acl during sidestep cutting. Clinical Biomechanics (Bristol, Avon), 19, 828-838.

McLean, S.G., Walker, K., Ford, K.R., Myer, G.D., Hewett, T.E., \& Van den Bogert, A. (2005). Evaluation of a two dimensional analysis method as a screening and evaluation tool for anterior cruciate ligament injury. British Journal of Sports Medicine, 39, $355-362$.

Meeuwisse, W.H. (1994). Assessing causation in sport injury: A multifactorial model. Clinical Journal of Sport Medicine, 4, 166-170.

Meyers, M.C., \& Barnhill, B.S. (2004). Incidence, causes, and severity of high school football injuries on field turf versus natural grass: A 5-year prospective study. American Journal of Sports Medicine, 32, 1626-1638.

Mihalik, J.P., Ondrak, K.S., Guskiewicz, K.M., \& McMurray, R.G. (in press). The effects of menstrual cycle phase on clinical measures of concussion in healthy college-aged females. Journal of Science \& Medicine in Sport.

Muneta, T., Takauda, K., \& Yamamoto, H. (1997). Intercondylar notch width and its relation to the configuration and cross-sectional area of the anterior cruciate ligament: A cadaveric study. American Journal of Sports Medicine, 25, 69-72.

Myer, G.D., Chu, D.A., Brent, J.L., \& Hewett, T.E. (2008). Trunk and hip control neuromuscular training for the prevention of knee joint injury. Clinics in Sports Medicine, 27(3), 425-448.

Myklebust, G., Maehlum, S., Holm, I., \& Bahr, R. (1998). A prospective cohort study of anterior cruciate ligament injuries in elite norwegian team handball. Scandinavian Journal of Medicine \& Science in Sports, 8, 149-153.

Najibi, S., \& Albright, J.P. (2005). The use of knee braces, part 1: Prophylactic knee braces in contact sports. American Journal of Sports Medicine, 33, 602-611.

NIH. (1992). Surveillance Strategies, 1991. Paper presented at the Conference on Sports Injuries in Youth in Washington, D.C., January 2009.

Olsen, O.E., Myklebust, G., Engebretsen, L., \& Bahr, R. (2003). Relationship between floor type and risk of acl injury in team handball. Scandinavian Journal of Medicine \& Science in Sports, 13, 299-304. 
Orchard, J. (2002). Is there a relationship between ground and climatic conditions and injuries in football? Sports Medicine (Auckland, N.Z.), 32, 419-432.

Orchard, J., Seward, H., McGivern, J., \& Hood, S. (1999). Rainfall, evaporation and the risk of non-contact anterior cruciate ligament injury in the australian football league. The Medical Journal of Australia, 17, 304-306.

Ostenberg, A., \& Roos, H. (2000). injury risk factors in female European football. A prospective study of 123 players during one season. Scandinavian Journal of Medicine \& Science in Sports, 10, 279-285.

Packard, R.C. (2008). Chronic post-traumatic headache: Associations with mild traumatic brain injury, concussion, and post-concussive disorder. Current Pain and Headache Reports, 12, 67-73.

Palmieri-Smith, R.M., Thomas, A., \& Wojtys, E. (2008). Maximizing quadriceps strength after ACL reconstruction. Clinics in Sports Medicine, 27, 405-424.

Palmieri, R.M., Tom, J.A., Edwards, J.E., Weltman, A., Saliba, E.N., Mistry, D.J., et al. (2004). Arthrogenic muscle response induced by an experimental knee joint effusion is mediated by pre- and post-synaptic spinal mechanisms. Journal of Electromyography and Kinesiology, 14(6), 631-640.

Palmieri, R.M., Weltman, A., Edwards, J.E., Tom, J.A., Saliba, E.N., Mistry, D.J., et al. (2005). Pre-synaptic modulation of quadriceps arthrogenic muscle inhibition. Knee Surgery, Sports Traumatology, Arthroscopy, 13, 370-376.

Pasanen, K., Parkkari, J., Rossi, L., \& Kannus, P. (2008). Artificial playing surface increases the injury risk in pivoting indoor sports: A prospective one-season follow-up study in Finnish female floorball. British Journal of Sports Medicine, 42, 194-197.

Patel, D.R., \& Baker, R.J. (2006). Musculoskeletal injuries in sports. Primary Care. Clinics in Office Practice, 33, 545-579.

Peloso, P.M., Carroll, L.J., Cassidy, J.D., Borg, J., von Holst, H., Holm, L., et al. (2004). Critical evaluation of the existing guidelines on mild traumatic brain injury. Journal of Rehabilitation Medicine, 36, 106-112.

Reddy, C.C., Collins, M.W., \& Gioia, G.A. (2008). Adolescent sports concussion. Physical Medicine and Rehabilitation Clinics of North America, 19, 247-269.

Renstrom, P., Ljungqvist, A., Arendt, E., Beynnon, B., Fukubayashi, T., Garrett, W., et al. (2008). Non-contact ACL injuries in female athletes: An International Olympic Committee current concepts statement. British Journal of Sports Medicine, 42(6), 394-412.

Schickendantz, M.S., \& Weiker, G.G. (1993). The predictive value of radiographs in the evaluation of unilateral and bilateral anterior cruciate ligament injuries. American Journal of Sports Medicine, 21, 110-113.

Schwartz, L., Taylor, H.G., Drotar, D., \& Owen, K. (2003). Long-term behavior problems following pediatric traumatic brain injury: Prevalence, predictors, and correlates. Journal of Pediatric Psychology, 28(4), 251-263.

Shelbourne, K.D., Davis, T.J., \& Klootwyk, T.E. (1998). The relationship between intercondylar notch width of the femur and the incidence of anterior cruciate ligament tears: A prospective study. American Journal of Sports Medicine, 26, 402-408.

Simpson, G., \& Tate, R. (2007). Suicidality in people surviving a traumatic brain injury: Prevalence, risk factors and implications for clinical management. Brain Injury, 21(13-14), 1335-1351.

Sitler, M., Ryan, J., Hopkinson, W., Wheeler, J., Santomier, J., Kolb, R., et al. (1990). The efficacy of a prophylactic knee brace to reduce knee injuries in football: A prospective, randomized study at West Point. American Journal of Sports Medicine, 18(3), 310-315.

Slauterbeck, J.R., Fuzie, S.F., Smith, M.P., Clark, R.J., Xu, K.T., Starch, D.W., et al. (2002). The menstrual cycle, sex hormones, and anterior cruciate ligament injury. Journal of Athletic Training, 37(3), 275-280. 
Sokolove, M. (2008). Warrior girls: Protecting our daughters against the injury epidemic in women's sports. New York City: Simon \& Schuster.

Souryal, T.O., \& Freeman, T.R. (1993). Intercondylar notch size and anterior cruciate ligament injuries in athletes: A prospective study. American Journal of Sports Medicine, 21, 535-539.

Swaine, B.R., Tremblay, C., Platt, R.W., Grimard, G., Zhang, X., \& Pless, I.B. (2007). Previous head injury is a risk factor for subsequent head injury in children: A longitudinal cohort study. Pediatrics, 119(4), 749-758.

Swanik, C.B., Lepart, S., Giraldo, J.L., DeMont, R.G., \& Fu, F.H. (1999). Reactive muscle firing of anterior cruciate ligament-injured females during functional activities. Journal of Athletic Training, 34(2), 121-129.

Snyder-Mackler, L., De Luca, P.F., Williams, P.R., Eastlack, M.E., \& Bartolozzi, A.R. (1994). Reflex inhibition of the quadriceps femoris muscle after injury or reconstruction of the anterior cruciate ligament. Journal of Bone and Joint Surgery, 76, 555-560.

Teitz, C.C., Lind, B.K., \& Sacks, B.M. (1997). Symmetry of the femoral notch width index. American Journal of Sports Medicine, 25, 687-690.

Tierney, R.T., Sitler, M.R., Swanik, C.B., Swanik, K.A., Higgins, M., \& Torg, J. (2005). Gender differences in head-neck segment dynamic stabilization during head acceleration. Medicine and Science in Sports and Exercise, 37(2), 272-279.

Uhorchak, J.M., Scoville, C.R., Williams, G.N., Arciero, R.A., St. Pierre, P., \& Talyor, D.C. (2003). Risk factors associated with noncontact injury of the anterior cruciate ligament: A prospective four year evaluation of 859 West Point cadets. American Journal of Sports Medicine, 31, 831-842.

Urbach, D., Nebelung, W., Becker, R., \& Awiszus, F. (2001). Effects of reconstruction of the anterior cruciate ligament on voluntary activation of quadriceps femoris. Journal of Bone and Joint Surgery, 83, 1104-1110.

Urbach, D., Nebelung, W., Weiler, H.T., \& Awiszus, F. (1999). Bilateral deficit of voluntary quadriceps muscle activation after unilateral ACL tear. Medicine and Science in Sports and Exercise, 31(12), 1691. [AUQ2]

Whiting, W.C., \& Zernicke, R.F. (2008). Biomechanics of musculoskeletal injury (2nd ed.). Champaign, IL: Human Kinetics Publishers.

Wojtys, E.M., Huston, L., Boynton, M.D., Spindler, K.P., \& Lindenfeld, T.N. (2002). The effect of the menstrual cycle on anterior cruciate ligament injuries in women as determined by hormone levels. American Journal of Sports Medicine, 30, 182-188.

Wright, R.W., \& Fetzer, G.B. (2007). Bracing after ACL reconstruction. Clinical Orthopaedics and Related Research, 455, 162-168.

Yu, B., Herman, D., Preston, J., Lu, W., Kirkendall, D.T., \& Garrett, W. (2004). Immediate effects of a knee brace with a constraint to knee extension on knee kinematics and ground reaction forces in a stop-jump task. American Journal of Sports Medicine, 32, $1136-1143$.

Yu, W.D., Liu, S.H., Hatch, J.D., Panossian, V., \& Finerman, G.A.M. (1999). Effect of estrogen on cellular metabolism of the human anterior cruciate ligament. Clinical Orthopaedics and Related Research, 366, 229-238.

Yu, W.D., Panossian, V., Hatch, J.D., Liu, S.H., \& Finerman, G.A.M. (2001). Combined effects of estrogen and progesterone on the anterior cruciate ligament. Clinical Orthopaedics and Related Research, 383, 268-281.

Zazulak, B.T., Hewett, T.E., Reeves, N.P., Goldberg, B., \& Cholewicki, J. (2007). Deficits in neuromuscular control of the trunk predict knee injury risk: A prospective biomechanical-epidemiologic study. American Journal of Sports Medicine, 35, 1123-1130.

Zimbalist, A.S. (2001). Unpaid professional: Commercialism and conflict in big-time college sports. Princeton: Princeton University Press. 